\title{
Ann Based Maximum Power Point Tracker for Photo Voltaic Pumping System
}

\author{
BIJI.G. \\ Assistant Professor, Department of EEE, Govt College of Engineering, Kannur,India.
}

\begin{abstract}
The feasibility of using a solar photovoltaic array to drive water-pumping units for irrigation and drinking water in remote areas, where other sources of power are not available has been demonstrated. Solar energy, being very costly at present, is to be used very judiciously. Hence, it is very important that the SPV (Solar Photovoltaic) modules operate at its maximum power point all the time. As the insolation and temperature vary, the maximum power point of the SPV array also changes. Due to the relative high cost of solar cell, it is very important that maximum power is extracted out of the SCA to minimize the required size of the SCA and hence the cost of the pumping system. The modelling of maximum power point trackers (MPPTs) has become common to the control system of SPV water pumping systems by selecting the converter-chopping ratio of MPPT using ANN. The models are integrated by a simulation program MATLAB
\end{abstract}

Index Terms: ANN controller, array, chopping ratio, insolation, MPPT, SCA, and SPV

\section{Introduction}

India is poorly placed in energy resources. However, $16 \%$ of world population lives in India, only $0.6 \%$ of world's oil, $0.6 \%$ of natural gas, and 6\% of coal are in India .About $70 \%$ of electricity is produced by coalfired power plants. At the present rate of production, it is expected that coal may last for the next 100 years only. India has 700 billion $\mathrm{m}^{3}$ of natural gas reserves and is expected to last for the next 23 years. Proven oil resources of India are 765 million tones and may last for the next 24 years only. Hydropower potential is estimated to be $84 \mathrm{GW}$ at a $60 \%$ load factor and only $25 \%$ is tapped so far. It is evident that all energy resources based on fossil fuels has limitations in availability and will soon exhaust. Hence, the long-term option for energy supply lies with renewable energy sources. These resources are inexhaustible for the next hundreds of thousands of years. These sources include solar energy, bio energy, wind energy, geothermal energy, wave, tidal and OTEC.Of these the solar energy is very advantageous compared to other energy sources.

\subsection{Solar energy}

Sun is a sphere of intensely hot gaseous matter. The energy, the earth receives from the sun is so enormous and so lasting that the total energy consumed annually by the entire world is supplied in as short a time as a half hour. On a clear day, the sun's radiation on the earth can be $1000 \mathrm{w} / \mathrm{m} 2$ depending on the location. The sun is a clean and renewable energy source, which produces neither waste nor any pollution through its utilization ${ }^{[1]}$. This energy is typically converted into useful energy form through natural and man made processes. Photovoltaic (PV) is a technology in which radiant energy from the sun is converted to direct current (DC) electricity. That means, the light falling on a two-layer semiconductor device produces a photo voltage or potential difference between the layers. This voltage is capable of driving a current through an external circuit and thereby producing useful work.

Fig1 shows typical PV system configurations. Systems are distinguished considering several factors. The basic distinction is whether the load requires DC or AC power. Systems with AC loads require a DC-AC inverter. Another distinction is whether it is a so called standalone system or a utility integrated system. Standalone systems are not connected to the grid but may have other backup sources like a diesel generator. Applications are installed in remote locations, especially in developing countries. Utility integrated systems may deliver energy to the grid and draw energy from it when necessary. 


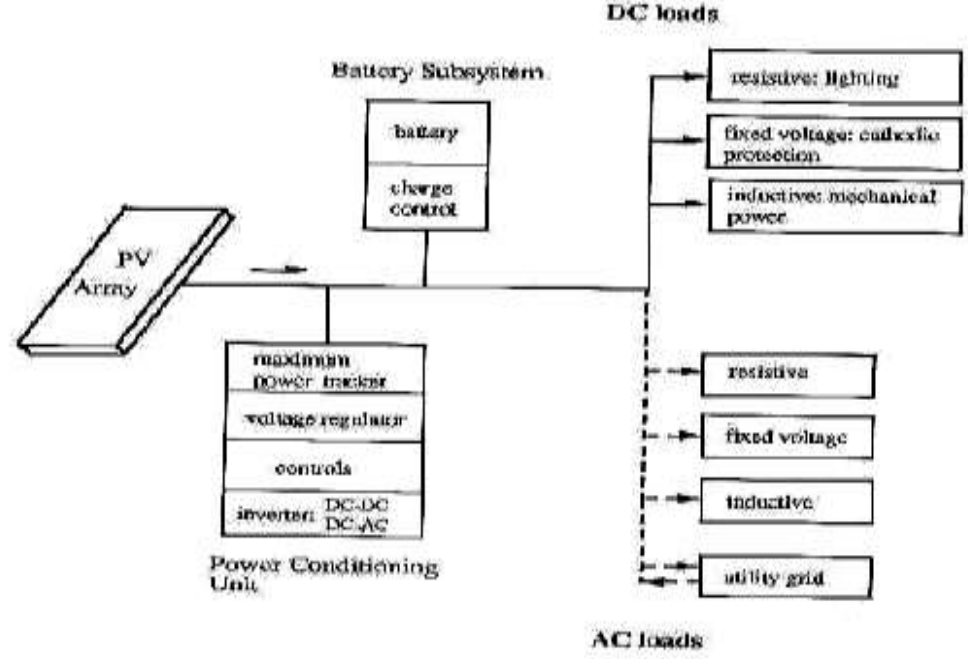

Fig 1 PV System configuration

The photovoltaic process is completely solid state and self-contained. There are no moving parts and no materials are consumed or emitted. The advantages that photovoltaic systems has over competing the power options

* While operating, they have no moving parts and produce power silently

* They are non polluting with no detectable emissions or odors.

* They can be stand-alone systems that reliably operate unattended for long periods.

* They may be combined with other power sources to increase system reliability.

* They can withstand severe weather conditions including snow and ice.

* They consume no fossil fuels -their fuel is abundant and free.

* They can be installed as modular building blocks as our power demand increases

* More photovoltaic modules may be added

\subsection{The origin of the solar cells}

Solar cells are devices, which convert solar energy directly into electricity, directly via the photovoltaic effect. Although the practical solar cells have only been available since mid 1950's. Scientific investigation of the photovoltaic effect started in 1839, when the French Scientist, Henri Becquerel discovered that an electric current could be reduced by shining a light into certain chemical solutions. The effect was first observed in a solid material in 1877. A silicon solar cell which converted 6\% of sun light falling onto it into electricity developed by Chapin, Pearson and Puller in 1954 and this kind of cells was used in specialized applications such as orbiting space satellites in 1958.

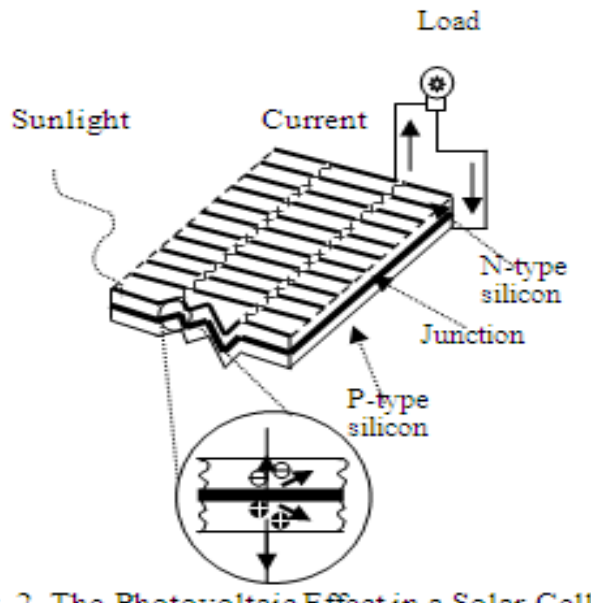

Fig. 2. The Photovoltaic Effect in a Solar Cell

The efficiency of a solar cell is defined as the ratio of the electrical output power over the sunlight input power. Today's commercially available silicon solar cells have efficiencies of about 10-18\%.Silicon solar cells are made using single crystal wafers, polycrystalline wafers or thin films. 
Unfortunately, solar cells are still far too expensive to produce a significant fraction of the worlds energy needs. However, as shown in fig, the cost of PV cells per watt of peak output has decreased dramatically since the 1970's Lowering the cost of photovoltaic electricity from solar cells is essential for the technology to further extend its use, especially among utilities.

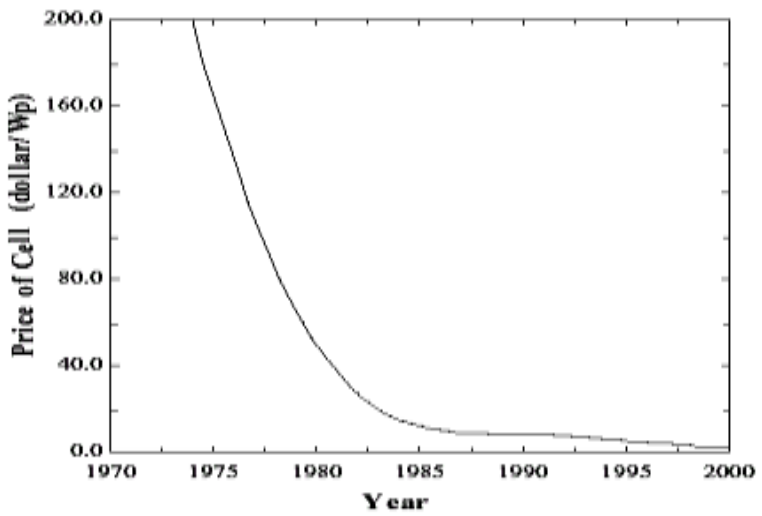

The major applications of PV technologies are

Fig. 3. Trend of Solar Cell Manufacturing Cost

Cathodic protection system

Electric fences

Remote lighting systems

Telecommunications,remotemonitoring systems

Solar powered water pumping

Rural electrification

Water treatment systems

\section{Photovoltaic Pumping System}

One promising area of research is the use of PV as the power source for pumping water. The use of photovoltaic power or water pumping is appropriate, as there is often a natural relationship between the availability of solar power and the water requirement increases during hot weather periods when the solar radiation levels are higher and the output of the solar array sis at a maximum. The water requirement decreases when the weather is cool and the sunlight is less intense.

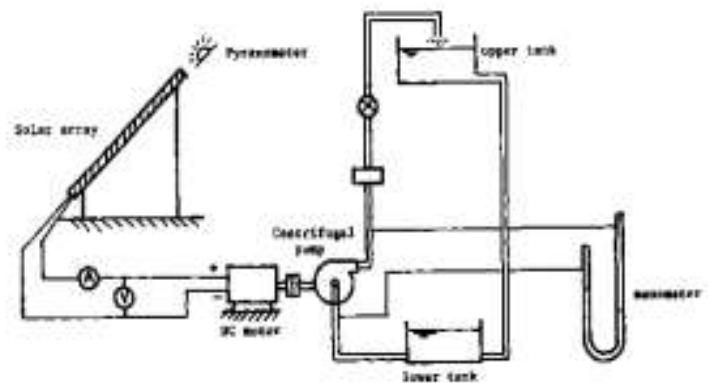

Fig.4. Layout of Pumping system components

Photovoltaic water pumping system is particularly suitable for water supply in remote areas where no reliable electricity supply is available

The usual elements of PV water pumping systems are

- Photovoltaic array, to produce the electricity supply to operate the pump. This supply could be direct current (DC) usually at 110 volts or alternating current, which is produced by inverting the DC power to $\mathrm{AC}$ power.

- Pump

- Battery storage if used, to provide electricity storage to allow pumping in cloudy conditions or at night

- Storage tank which normally elevated, serves a similar purpose to battery storage.

- Electronic devices to change the configuration of PV array at different radiation levels to improve the efficiency of the system. 
The amount of power available from a PV device is determined by

$\circ$ The type and area of the material

- The radiation level which is a measure of the sun's available energy

- The conversion efficiency of the PV array

- The slope of the pv array

The ambient temperature

The pump motor hydraulic system

Unlike a battery, a PV array is a non-linear DC source and its operation has to be carefully matched top that of its equivalent electrical load in order to extract maximum available energy. The PV cell can be represented by its VI characteristics as shown in fig

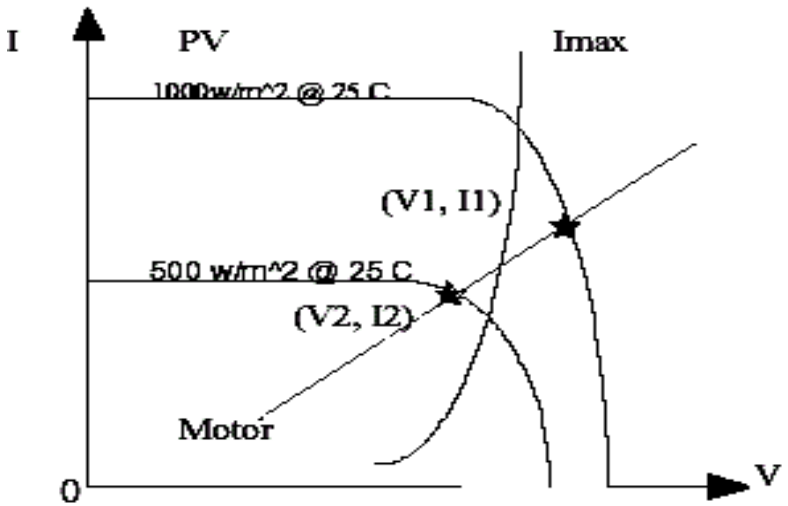

Fig. 5. The maximum operating points of PV pumping system

An important feature of PV cells is that the voltage of the cell downs not depend on its size, and remains constant with change in light intensity. However, the current in a device is almost directly proportional to light intensity and size. One important component of PVPS is the pump. A dc pump is used in most of PV pumping system, which consists of a dc motor and centrifugal pump. Most popularly separately excited dc motor and induction motor are considered. The circuit diagrams DC motors are investigated.

\section{Proposed Work}

The matching between the PV generator and two types of motor ,the separately excited dc motor and the induction motor, both driving a centrifugal pump load are analyzed in order to maximize the mechanical power obtained $^{[2]}$. The maximum mechanical power characteristics at different insolation levels are derived by proper methods and these are found to depend on the motor type and parameters a well as the torque slip characteristics of the load.

In the case of the separately excited dc motor, it is possible to extract the maximum mechanical power by controlling the motor to the PV array. The analysis carried out results in defining the optimum operation line $\mathrm{p}^{*}$. the operation in this case is controlled to the $\mathrm{p}^{*}$ line, the locus of the motor's gross mechanical power operating points, by proper selection of the motor parameters and control of the motor excitation.

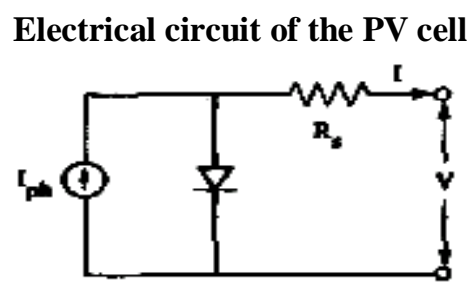

Fig.6. Equivalent circuit of PV cell

The PV generator consists of an array of solar cell modules connected in series parallel combinations to provide the desired dc voltage and current.

The terminal voltage of each cell is given by

$$
\mathrm{V}=\frac{A k T}{q} \ln \frac{(I p h-I+I o)}{I o}-R s . I
$$


$I=$ current drawn from the cell; $I p h=$ cell photocurrent proportional to insolation; $I_{0}=$ Cell reverse saturation current; $\mathrm{R}_{\mathrm{s}}=$ cell series resistance; $\mathrm{q}=$ electroncharge; $\mathrm{A}=$ completion factor; $\mathrm{k}=$ Boltzman constant;

$\mathrm{T}=$ absolute temperature

The solar cell is a nonlinear device and cab be represented by its V-I characteristics as shown in figure.

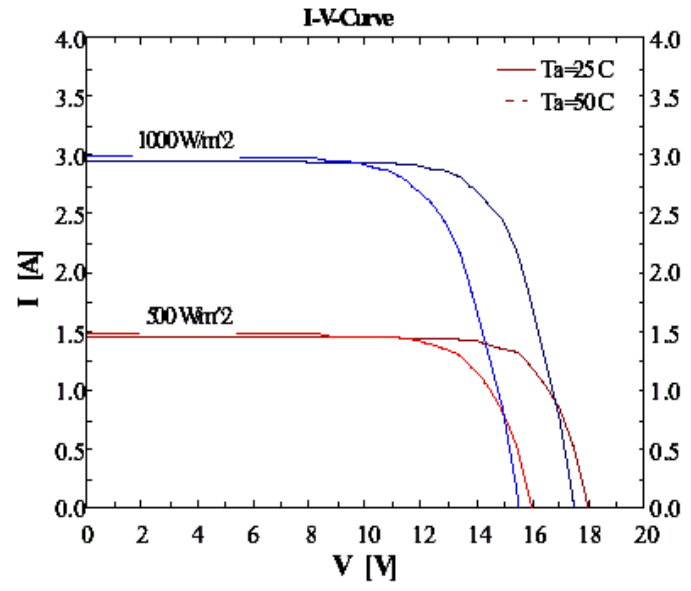

Fig.7 V-I characteristics of a solar cell

The PV generator possess a maximum power line $\mathrm{P}_{\max }$ corresponding to the maximum power that the generator can deliver at various insolation levels.

For more convenient to deduce the equation for the maximum power line in the form $\mathrm{V}_{\max }=\mathrm{kI}^{\alpha}{ }_{\max }$

Where $\mathrm{k}$ and $\alpha$ are assumed to be constant parameters for the array which depend on the type of solar cells used, the number of strings in parallel, the number of modules in series and the number of cells per module

IV.

Separately Excited D.C Motor

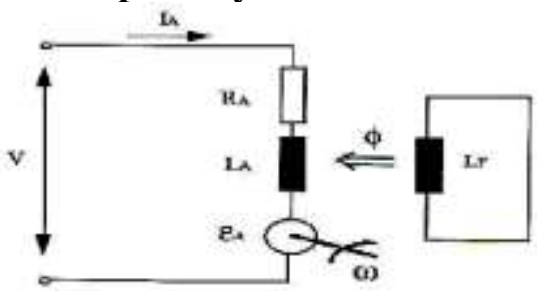

Fig. 8. Circuit Diagram of Separately excited D.C Motor

From the equivalent circuit of the separately excited D.C Motor, we can write
$V=I R_{a}+E_{b}$
$E_{b}=C W$

The torque speed characteristic of the centrifugal pump load can be represented in the form

$E_{b}=B W^{2}$

From the above equations (3), (4) as

$V=C^{1.5} \sqrt{T / B}+I R_{a}$

The output mechanical power can be written as

$P_{m}=I V-I^{2} R_{a}$

For maximum mechanical power

$I^{*}=V^{*} /\left(2 R_{a}-V^{*}\right)$

$\mathrm{V} *$ is always negative. If we assume $\mathrm{Ra}=0$, then the mechanical power will equal the electrical 


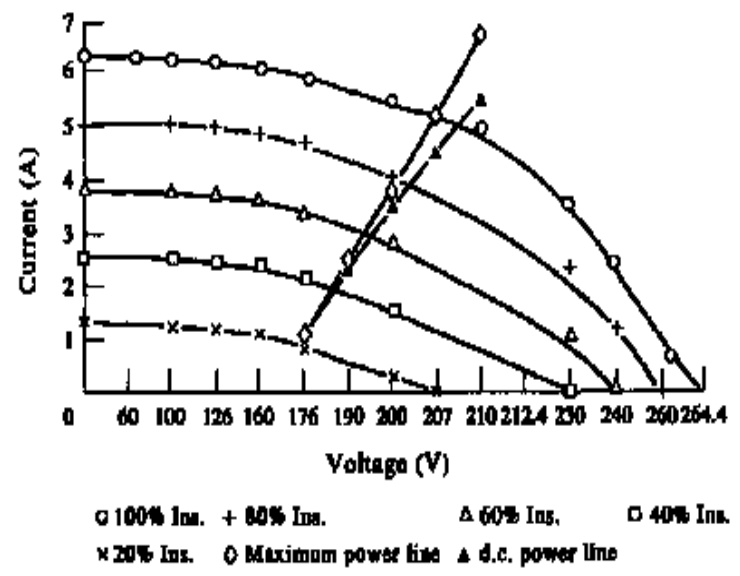

Fig. 9. PV characteristics with the Pmax and P* lines for D.C .motor

Which with the $\mathrm{P}^{*}$ line will result in a single operating point $\left(\mathrm{I}^{*}, \mathrm{~V}^{*}\right)$ giving maximum mechanical power at each insolation level. If by the proper choice of the motor parameters and control of the field current at each insolation level, the motor operation can be controlled to satisfy the required condition.

The cost of photovoltaic installations is mostly dependent on the PV array area. The major disadvantages of using PV are their high installation costs and its low energy conversion efficiency $(\eta)$. Therefore, in order to improve the cost effectiveness of PV array powered systems, the electric power generated by the PV array should be efficiently utilized. For that different system configurations are used

$>$ Direct coupled system

$>$ Battery buffered system

$>$ With ac system

$>$ With battery back up in using ac system

$>$ Maximum power point tracker(MPPT)

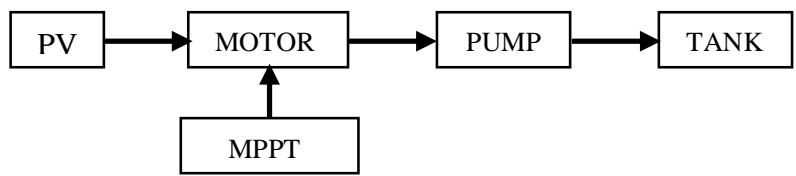

\section{Maximum Power Point Tracking}

MPPT is an electronic DC-DC converter that optimizes the match between the solar array and the battery bank, dc motor/pump ${ }^{[3]}$. By matching the PV array to the motor by means of an MPPT, the motor operation can be improved. MPPT controllers are a refinement of the old LCB (Linear Current Booster) controls often still used on solar powered pumps.

MPPT is an electronic tracking, the controller looks at the output of the panels and compares it to the battery voltage. It then figures out what is the absolute best power that the panel can put out. It takes this and converters it to the best voltage to get maximum amps into the battery

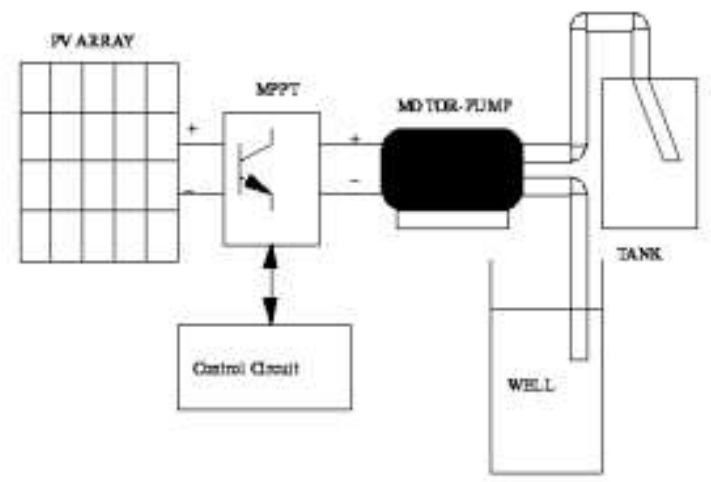

Fig. 11. Maximum Power Point Tracking of PVPS

A SPV module is not a fixed power source, even though it is a limited power source. The energy extracted from the solar array is strongly limited by the physical constraints of PV cells. The approximate power 
density of the isolation on a sunny day is around $1000 \mathrm{~W} / \mathrm{m} 2$. In combination with solar cells efficiencies between $15 \%$ and $17 \%$, these yield a maximum possible power output between $150 \mathrm{~W} / \mathrm{m} 2$ and $170 \mathrm{~W} / \mathrm{m} 2$. There are two ways to increase the power company from a photovoltaic array. One can add more panels to the array, which means an increase in area requirement and a great increase in cost for material. One can also attempt to extract the maximum power output of the exciting array. For these, one has to make sure that the array always works at its highest possible efficiency and the array always phases the sun.

The power output of a solar panel is greatly reduced for a decreasing insolation and increase in panel temperature.The value for the optimum operating voltage Vmp will vary constantly with changes in these environmental conditions. In these circumstances, a maximum power point tracking (MPPT) mechanism can help to significantly increase the power output of a solar power system by adjusting the system load in such a way that the operating voltage $\mathrm{V}$ will always be approximately equal to the operating voltage $\mathrm{Vmp}$

$\mathrm{V}=\mathrm{Vmp}+\varepsilon$

With $\mathcal{E}$ being as small as possible. The importance of keeping the operating voltage as possible to Vmp. If the operating voltage differs from Vmp by about $10 \%$, it will result in output power reduction of almost $25 \%$. Comparison of systems with and without maximum power point tracking devices shows that units with an MPPT output $80-90 \%$ of their theoretical Power, where as units without an MPPT only operate at $30 \%$ of their maximum power output.

\subsection{Calculation of chopping ratio for maximum power operation of array}

For maximum utilization of array, a power converter is introduced in between array and motor. The chopping ratio of the converter is changed accordingly to match the motor load to the array. The required value of the chopping ratio at which the chopper should operate for maximum power transfer to happen, can be calculated as below using the mathematical models of the components developed.

Assuming the power converter is ideal at maximum power point, the power absorbed by the motor is equal to the power delivered by the array i.e.

$\mathrm{P}_{\mathrm{m}}=\mathrm{V}_{\mathrm{av}} \mathrm{I}_{\mathrm{av}}=\mathrm{V}_{\mathrm{mp}} \mathrm{I}_{\mathrm{mp}}$

Where $\mathrm{V}_{\mathrm{av}}$ and $\mathrm{I}_{\mathrm{av}}$ are the motor armature voltage, current, $\mathrm{V}_{\mathrm{mp}}$ and $\mathrm{I}_{\mathrm{mp}}$ are SCA voltage current respectively at maximum power point of SCA. The motor armature voltage and currents are expressed in terms of SCA voltage, current at maximum power point as

$\mathrm{V}_{\mathrm{av}}=\mathrm{Y}_{\mathrm{mp}} \mathrm{V}_{\mathrm{mp}}$
$\mathrm{I}_{\mathrm{av}}=\mathrm{I}_{\mathrm{mp}} / \mathrm{Y}_{\mathrm{mp}}$
$\mathrm{V}_{\mathrm{av}}=\mathrm{E}_{\mathrm{b}}+\mathrm{I}_{\mathrm{av}} \mathrm{R}_{\mathrm{a}}$

The motor armature voltage equation in terms of SCA voltage, current is

$\mathrm{Vmp}=(\mathrm{Eb} / \mathrm{Ymp})+\operatorname{Imp}\left(\mathrm{Ra} / \mathrm{Y}^{2} \mathrm{mp}\right)$

Rearranging the above equation

vmpY ${ }^{2}$ mp-EbYmp-ImpRa=0

For the above equation, two solutions exist. Since the chopping ratio can never be positive, expression that gives negative duty ratio is

$Y m p=E_{b} / 2 V_{m p}+\left(\left(E_{b} / 2 V_{m p}\right)^{2}+\left(I_{m p} R_{a} / V_{m p}\right)\right)^{1 / 2}$

For a given SCA maximum power, the motor armature current is obtained from the following equations

$\mathrm{Pm}=$ EbIav-I $\mathrm{I}^{2} \mathrm{avRa}$

Rearranging the equation

$\mathrm{RaI}^{2} \mathrm{av}+\mathrm{EbIav}-\mathrm{Pmp}=0$

Solving equation (17) for Iav we get

$I a v=E_{b} / 2 V_{m p}+\left(\left(E_{b} / 2 V_{m p}\right)^{2}+\left(P_{m p} / R_{a}\right)\right)^{1 / 2}$

Where $\mathrm{Eb}$ is given by $\mathrm{C}_{\mathrm{e}} \omega$. The chopping ratio ${ }^{[4]}$ of the converter depends on the motor back EMF, which in turn depends on the motor load. Once back EMF is calculated corresponding Pm. The chopping ratio of the converter is obtained from the eqn. These computed values are taken as reference patterns for training the Neural Network.

\section{Simulation Of The Network}

Usually the entire reference pattern is not fed to the network during training. Instead, a portion of the data is set apart for testing the trained network for its generalization and extrapolation capability. The simulation of the network can be done using the "simuff". If the values ${ }^{[5]}$ of the output simulated by the network are within desired limits of the actual value, the network can be considered to be adequately trained. Otherwise, the network will have to be trained using more data or will have to be redesigned. 
Separate MATLAB programs, which can carry out ${ }^{[6][7]}$ all the steps of the design of the ANN controller are written, one using 'tanh' as the sigmoid function and another using 'log' as the sigmoid function. These programs design two layer ANN controller for the given.

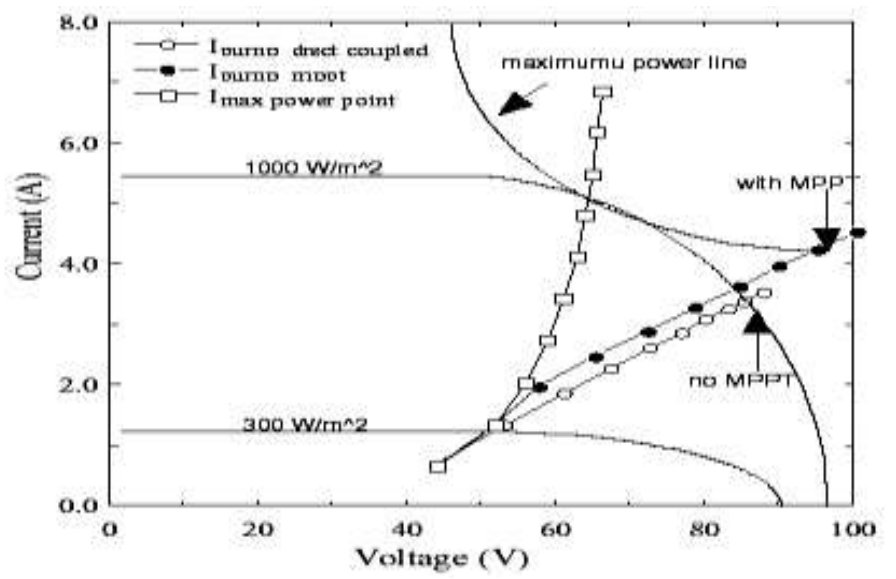

Fig.12. I-V curve of a directly coupled PVPS and a PVPS with an MPPT

\section{Conclusion}

This paper presents modelling and simulation of the photovoltaic pumping systems for maximum efficiency operation. Here the output of different models were analyzed Economical analysis was also carried out for each models. From the two results, the modelling using MPPT is very advantageous and economical.

\section{References}

[1]. Mona N.Eskander and Aziza M.Zaki,'Maximum Efficiency Photovoltaic Induction Motor Pump system', Proceedings on Renewable Energy, Vol.10, No.1, pp.53-60, March 1997.

[2]. Mehmet Akbaba, Isa Qamber, and Adel Kamal,'Matching of separately excited DC motors to Photovoltaic Generators for maximum efficiency operation', Proceedings on Solar energy, Vol.63, No.6, pp.375-385, September 1998.

[3]. M.M.Saied,'Matching of D.C. motors to photovoltaic generator for maximum gross mechanical energy', IEEE Transactions on Energy Conversion, Vol.EC-3, No.3, pp.465-472, September 1988.

[4]. D.Langridge,W.Lawrance and B.Wichert,'Development of a photovoltaic pumping system using a Brushless DC motor and Helical Rotor pump', Proceedings on Solar Energy,Vol.56,No.2,pp.151-160,March 1996.

[5]. A.Al-Karaghouli, A.M.Al-Sabounchi,'A PV pumping system', Proceedings on Applied energy, Vol.65, pp.145-151, August 2000.

[6]. Q.Kou, S.A.Klein AND W.A.Beckman,'A method for estimating the long-term performance of direct coupled PV pumping systems',Unversity of Wisconsin Solar Energy Laboratory, Madison.

[7]. Z.Zinger,A.Braunstein,'Optimum operation of a combined system of a solar cell array and a D.C motor',IEEE Transactions on Power Apparatus and Systems',Vol.PAS-100,No.3,pp.1193-1197,March 1981. 